\title{
DO CADÁVER E DAS PARTES DO CORPO HUMANO E O REGISTRO NO LIVRO "F" DO OFICIAL DO REGISTRO CIVIL E DAS PESSOAS NATURAIS
}

Francis Pignatti do Nascimento*

Renato Bernardi ${ }^{* *}$

SUMÁRIO: Introdução; 2 Do Direito do Cadáver e das Partes do Corpo Humano; 3 Do Registro Civil e das Pessoas Naturais face ao Direito do Cadáver; 4 Da Criação do Livro "F" - do Registro de Partes do Corpo Humano no Oficial do Registro Civil e das Pessoas Naturais e da "DOPC" - Declaração de Óbito de Parte do Corpo; 5 Da Tutela Penal e Civil do Cadáver; 6 Ideologia de Projeto de Lei Federal (Criação do Livro "F" e Criação da "DOPC") Alterando a Lei 6.015/1973; 7 Considerações finais; Referências.

RESUMO: O presente trabalho estuda a prática dos sepultamentos de partes do corpo humano sem o registro no Oficial do Registro Civil e das Pessoas Naturais face à ausência de legislação federal estabelecendo o "registro de partes de corpo humano". A Lei 6.015/1973 e a Lei 8.935/1994 são os estatutos legais que cuidam dos registros públicos. Mas a falta de legislação estabelecendo os registros de partes do corpo humano nos Oficiais do Registro Civil e das Pessoas Naturais configura uma ausência legal de preservação destes direitos da personalidade, intimamente ligados pela Teoria do Prolongamento do Corpo Vivo. Na utilização do método dedutivo se conclui que a criação do Livro "F" nos Oficiais do Registro Civil e das Pessoas Naturais é o único meio capaz de garantir o exercício deste direito, haja vista que somente com o Registro Público destes fatos notórios existirá proteção dos direitos da personalidade.

PALAVRAS-CHAVE: Cremação; Direitos Humanos; Inovações legislativas; Registro Civil; Sepultamento.

\section{THE CORPSE AND PARTS OF THE HUMAN BODY AND THE REGIS- TRATION IN BOOK "F” OF CIVIL REGISTRATION AND NATURAL PERSONS}

ABSTRACT: Current paper analyzes the burial of parts of the human body without

\footnotetext{
"Universidade Estadual do Norte do Paraná (UENP), Brasil. E-mail: fpignatti@terra.com.br

** Doutor em Direito do Estado pela PUC/SP. Docente efetivo dos cursos de Bacharelado, Mestrado e Doutorado, Coordenador do TCC e Membro da Comissão de Coordenação do Programa de Mestrado em Ciência Jurídica da Faculdade de Direito do CCSA/UENP, Campus de Jacarezinho, PR, Brasil.
} 
any registration by the Officer of Civil Registration and Natural People in the wake of the lack of federal legislation establishing 'the registration of parts of the human body'. Laws 6015/1973 and 8935/1994 are the legal statutes that deal with public registration. The lack of legislation establishing registers of parts of the human body by Officers of the Civil Registration and Natural People is a loophole in the preservation of rights of personality closely linked to the Theory of the Prolongation of the Living Body. Results show that the establishment of Book F by the Officers of Civil registration and Natural Persons is the sole guarantee of the right. The protection of the rights of the personality exists when these facts are entered into the Public Register.

KEY WORDS: Burial; Cremation; Civil register; Human rights; Legislative innovations.

\section{DEL CADÁVER Y DE LAS PARTES DEL CUERPO HUMANO Y EL RE- GISTRO EN EL LIBRO “F” DEL OFICIAL DEL REGISTRO CIVIL Y DE LAS PERSONAS NATURALES}

RESUMO: En la presente investigación se estudia la práctica de los entierros de partes del cuerpo humano sin el registro en el Oficial do Registro Civil y de las Personas Naturales delante a la ausencia de legislación federal estableciendo el "registro de partes de cuerpo humano". La Ley 6.015/1973 y la Ley 8.935/1994 son los estatutos legales que cuidan de los registros públicos. Pero la falta de legislación estableciendo los registros de partes del cuerpo humano en los Oficiales del Registro Civil y de las Personas Naturales configura una ausencia legal de preservación de estos derechos de la personalidad, íntimamente ligados por la Teoría del Prolongación del Cuerpo Vivo. En la utilización del método deductivo se concluye que la creación del Libro "F" en los Oficiales del Registro Civil y de las Personas Naturales es el único medio capaz de garantizar el ejercicio de este derecho, puesto que solamente con el Registro Público de estos hechos notorios existirá protección de los derechos de la personalidad.

PALABRAS CLAVE: Entierro; Cremación; Registro Civil; Derechos Humanos; Innovaciones legislativas.

\section{INTRODUÇÃO}

O Direito ao Cadáver é tema de total relevância ao mundo jurídico, principalmente por estar totalmente ligado aos Direitos da Personalidade e sua real relevância ao Princípio da Dignidade da Pessoa Humana. A manifestação de vontade do 
titular do corpo "agora sem vida" deve ser respeitada, levando em consideração o Princípio da Vontade, o qual possui correlação com a Teoria do Prolongamento do Direito ao Corpo Vivo, ou seja, o corpo sem vida possui uma correlação de perpetuidade de certos direitos da personalidade, produzindo efeitos post mortem.

O nascituro, cuja existência é intrauterina, não deve ser confundido com outra figura, a do natimorto que é a criança que nasceu morta, ou seja, todo natimorto foi antes um nascituro, mas nem todo nascituro será um natimorto. A morte faz cessar a capacidade corporal da consciência, mas o cadáver possui prerrogativas comuns aos direitos da personalidade, sendo ressaltada a extracomercialidade do corpo, haja vista que a disposição somente é possível se estiver vinculada aos fins altruísticos ou científicos.

Ademais, a força das religiões inspira o direito ao tema influenciando diretamente o direito ao culto e o respeito à memória dos mortos, destacando-se a definição de crimes contra o sentimento religioso e o respeito aos mortos. Embora a questão se revele aparentemente simples, já que o que se está a discutir é a conservação dos corpos de pessoas que já não mais fazem parte do mundo do ser, seu desdobramento é imensurável.

Quando se fala em registros públicos é certo o pensamento de que pelo menos em duas ocasiões todas as pessoas vão precisar do Oficial do Registro Civil e das Pessoas Naturais: quando nascem e quando morrem. No caso do nascimento, é feito o registro de nascimento, que dá início à personalidade civil, que permite o exercício da cidadania. Já com a morte, é preciso fazer o registro de óbito, documento que prova o fim da existência da pessoa humana.

O Oficial do Registro Civil e das Pessoas Naturais é considerado um serviço essencial na República Federativa do Brasil e em cada Serventia Extrajudicial do Oficial do Registro Civil e das Pessoas Naturais haverá os seguintes livros: Livro "A" - de registro de nascimento; Livro "B" - de registro de casamento; Livro "B Auxiliar" - de registro de casamento Religioso para Efeitos Civis; Livro " $\mathrm{C}$ " - de registro de óbitos; Livro "C Auxiliar" - de registro de natimortos; Livro "D" - de registro de proclama; Livro "E" - de registro de emancipação, interdição, ausência, morte presumida, sentença de separações judiciais e consensuais, dissoluções de casamentos de estrangeiro, conversões de divórcio, divórcio direto, nulidades e anulações de casamentos, resultantes de mandados judiciais, opção de nacionalidade.

É necessário salientar que o corpo humano sempre despertou grande inte- 
resse de estudo. A problemática se funda na importância dos Registros de Parte do Corpo face os casos de amputação de membros, haja vista que a Lei 6015/1973 em seu artigo 29 não estabelece o registro de partes do corpo humano no Oficial do Registro Civil e das Pessoas Naturais.

O "Registro de Partes do Corpo Humano" no Oficial do Registro Civil e das Pessoas Naturais consolida a ideia de que a personalidade está intimamente ligada à pessoa, pois exprime aptidão genérica para adquirir direitos e contrair obrigações. Os direitos da personalidade são aqueles inerentes à pessoa e à sua dignidade, surgindo cinco ícones principais (vida, honra, imagem, nome e intimidade).

Pensar na criação de Lei que estabeleça o surgimento do ("Livro F" - do registro de parte do corpo humano no Oficial do Registro Civil e das Pessoas Naturais e da "DOPC" - Declaração de Óbito de Parte do Corpo) é uma forma de garantir os direitos daqueles que possuem partes do seu corpo amputados pelas diversas situações possíveis.

Aos médicos é proibido emitir DO (Declaração de Óbito) para o caso de amputação, e em conformidade com a legislação vigente nada deve ser levado ao Oficial do Registro Civil e das Pessoas Naturais, pois a amputação de um membro não caracteriza a morte (Livro C) ou a diminuição da importância da pessoa natural (Livro E), não devendo ser objeto de qualquer tipo de publicidade, estando o "Livro F" e a "DOPC" pelo Ministério da Saúde hábil na garantia dos direitos da personalidade de partes do corpo humano (hoje) sepultamentos sem registro em cartório.

O estudo em comento enfocou uma análise da legislação de Registros Públicos envolvendo partes do corpo humano, atrelada ao direito da personalidade, de modo que a efetividade deste direito somente será possível após a criação do Livro "F" pelo Poder Legislativo Federal.

Este objeto de estudo tem por justificativa a proteção dos direitos da personalidade em face da legislação atual brasileira, visando à garantia dos direitos daqueles que passam pela dolorosa situação de terem membros do corpo humano amputados e não conseguem na legislação os meios necessários ao exercício dos seus direitos.

À vista disso, a problemática suscitada está pautada no fato de que a ausência de Livro específico "F" nos Oficiais do Registro Civil e das Pessoas Naturais por falta de previsão legislativa gera uma omissão que recai na violação dos direitos da personalidade previstos na Constituição Federal de 1988, no Código Civil brasileiro 
e na análise da Teoria do Prolongamento do Corpo Vivo.

No seguimento de tal ideia, o objetivo posto buscou analisar algumas dificuldades para efetivação do direito da personalidade a partir da ausência de previsão legislativa na garantia deste direito, ao impossibilitar, por meio de instrumentos reais, o exercício pleno das inúmeras pessoas que passam por esta realidade no seu dia a dia e não conseguem o registro público do fato notório ocorrido.

Para resolver a problemática foi empregado o método dedutivo de maneira que se utilizou de uma premissa geral de maior abrangência para se alcançar singularidades do tema proposto que afunilaram a questão até o ponto central a ser trabalhado, qual seja, o direito da personalidade de partes do corpo humano que infelizmente ficam desprotegidas do amparo jurídico pela ausência de disposição legal passível de registros públicos nos Oficiais do Registro Civil e das Pessoas Naturais.

Em auxílio ao método empregado, igualmente foram utilizadas técnicas de pesquisa como a pesquisa indireta documental, por meio da Constituição Federal de 1988 e da Lei n ${ }^{\circ}$ 6015/1973 e pesquisa indireta bibliográfica com a utilização de livros e reportagens, todos relacionados, de alguma forma, com o tema proposto.

\section{DO DIREITO DO CADÁVER E DAS PARTES DO CORPO HUMANO}

As pessoas adquirem personalidade quando do seu nascimento com vida, mas o evento morte não extingue por completo os direitos da personalidade. $\mathrm{O}$ artigo $6^{\circ}$ do Código Civil de 2002 ensina que "a existência da pessoa natural termina com a morte", mas muitos questionamentos giram em torno do fim da personalidade. Para Bittar, cadáver significa "o corpo sem vida" ${ }^{3}$. Mas o fim da vida não significa o desaparecimento dos direitos.

Ademais, o cadáver possui proteção jurídica em muitos dispositivos nacionais, tais como a Lei $n^{\circ} 8.501 / 1992$ (que dispõe sobre a destinação de cadáveres não reclamados junto às autoridades públicas) ${ }^{04}$, Lei no $9.434 / 1997$ (que dispõe sobre a remoção de Órgãos, Tecidos e Partes do Corpo Humano para fins de transplante

${ }^{03}$ BITTAR, Carlos Alberto. Os direitos da Personalidade. $6^{\mathrm{a}}$ ed. atualizada por Eduardo Carlos Bianca Bittar. Rio de Janeiro: Forense Universitária, 2003. p. 91.

${ }^{04}$ BRASIL. Lei $\mathrm{n}^{\circ} 8.501$, de 30 de novembro de 1992. Dispõe sobre a utilização de cadáver não reclamado, para fins de estudos ou pesquisas científicas e dá outras providências. Disponível em: < http://www2. camara.leg.br/legin/fed/lei/1992/lei-8501-30-novembro-1992-363726-publicacaooriginal-1-pl.html> Acesso em: 20 jun. 2018. 
e tratamento e dá outras providências) ${ }^{05}$, bem como o artigo12 do Código Civil ${ }^{06}$, artigos 209 a 212 do Código Penal brasileiro ${ }^{07}$, artigo $1^{\circ}$, inciso III da Constituição Federal de $1988^{08}$.

A morte não retira a dignidade da pessoa que faleceu. Portanto, existe amparo legal, pois a dignidade sendo um dos princípios fundamentais, que regem a vida dos cidadãos, bem como os resguardam após a morte, vem a disciplinar determinadas medidas que devem ser respeitadas, sendo que o Princípio da Dignidade da Pessoa Humana envolve todos os direitos fundamentais.

Ademais, parte da doutrina entende que o cadáver é uma coisa fora do comércio, isso significa que não se pode vender um cadáver ou partes de seu corpo, podendo ser doados gratuitamente com prévia anuência do falecido ou dos familiares, nos termos da Lei $n^{0}$ 9.434/1997. A posição que tem maior predominância nos dias atuais é a que determina que a natureza jurídica do cadáver seja um direito pessoal.

Nas palavras de Jean Ziegler:

Os mortos continuam a agir para além da morte. Os cadáveres se dissolvem, mas as obras que eles criaram, as instituições que animaram, as ideias que lançaram ao mundo, os afetos que suscitaram continuam a agir e a fermentar. Quando um corpo volta ao nada, a consciência segue um destino social entre os vivos ${ }^{09}$.

O cadáver possui direito de personalidade, o que se verifica através da interpretação do artigo 12 e parágrafo único do Código Civil de 2002, sendo que existe uma extensão dos direitos da personalidade que serão exercidos pelos familiares do falecido:

Artigo 12. Pode-se exigir que cesse a ameaça, ou a lesão, a di-

${ }^{05}$ BRASIL. Lei $\mathrm{n}^{0}$ 9.434, de 4 de fevereiro de 1997. Dispõe sobre a remoção de órgãos, tecidos e partes do corpo humano para fins de transplante e tratamento e dá outras providências. Disponível em: $<\mathrm{http}: / /$ www.planalto.gov.br/CCIVIL_03/Leis/L9434.htm> Acesso em: 20 jun. 2018.

${ }^{06}$ BRASIL. Lei ${ }^{0}$ 10.406, de 10 de janeiro de 2002. Institui o Código Civil. Disponível em: < http://www. planalto.gov.br/ccivil_03/leis/2002/110406.htm> Acesso em: 20 jun. 2018.

${ }^{07}$ BRASIL. Decreto-Lei $\bar{n}^{\circ} 2.848$, de 7 de dezembro de 1940. Código Penal. Disponível em: < http://www.planalto.gov.br/ccivil_03/decreto-lei/Del2848compilado.htm > Acesso em: 20 jun. 2018.

${ }^{08}$ BRASIL. Constituição da República Federativa do Brasil. Brasília: Senado Federal, 1988. Disponível em: $<$ http://www.planalto.gov.br/ccivil_03/constituicao/Constituicao.htm> Acesso em: 20 jun. 2018.

${ }^{09}$ SILVA, Justino Adriano Farias da. Direito Penal Funerário. Porto Alegre: Livraria do Advogado, 1992. p. 2122. 
reito da personalidade, e reclamar perdas e danos, sem prejuízo de outras sanções previstas em lei. Parágrafo único. Em se tratando de morto, terá legitimação para requerer a medida prevista neste artigo o cônjuge sobrevivente, ou qualquer parente em linha reta, ou colateral até o quarto grau ${ }^{10}$.

As pessoas legitimadas a atuarem em nome do falecido são: o cônjuge, descendentes, ascendentes e os colaterais em linha reta até o $4^{\mathrm{o}}$ grau, sendo atribuído este direito por exclusão, ou seja, primeiramente cabe ao cônjuge, na falta deste, aos descendentes e assim sucessivamente.

A doação de órgãos, ou partes do corpo para os doentes que necessitam de um transplante, também pode ser consentida pelos familiares. O artigo 8 da Lei 9.434/1997 ensina que após a retirada de tecidos, órgãos e partes, o cadáver será imediatamente necropsiado, se verificada a hipótese do parágrafo único do artigo 7, e, em qualquer caso, condignamente recomposto para ser entregue, em seguida, aos parentes do morto ou seus responsáveis legais para sepultamento ${ }^{11}$.

Também, o direito a partes separadas do corpo é um tema recorrente dos dias atuais. A separação somente é possível quanto a partes destacáveis do corpo (renováveis ou não renováveis), sendo que a extirpação deve perfazer-se para salvamento da vida ou para preservação da saúde do interessado, típicos casos de amputação de membros e transplantes.

No Brasil não é permitido ao paciente manter o membro amputado em casa, podendo ser punido com normas legais específicas que impedem a prática em razões de prescrições de ordem pública, em especial sanitárias. A proteção destes direitos deve ser respeitada em conformidade com o Princípio da Dignidade da Pessoa Humana.

A criação de dispositivos legais que determinem os assentos de partes do corpo humano em Oficiais do Registro Civil e das Pessoas Naturais é medida positiva na proteção destes direitos. Ocorrendo alguma afronta aos direitos da personalidade relacionados ao cadáver o Poder Judiciário será acionado e o protegerá mediante as ações cíveis e penais que são cabíveis.

Não se pode deixar de falar da exposição mundial Human Bodies que

\footnotetext{
${ }^{10}$ BRASIL. Lei $\mathrm{n}^{\mathrm{0}} 10.406$, de 10 de janeiro de 2002. Institui o Código Civil. Disponível em: < http://www. planalto.gov.br/ccivil_03/leis/2002/10406.htm> Acesso em: 20 jun. 2018.

${ }^{11}$ BRASIL. Lei $\mathrm{n}^{\circ} 9.434$, de 4 de fevereiro de 1997. Dispõe sobre a remoção de órgãos, tecidos e partes do corpo humano para fins de transplante e tratamento e dá outras providências. Disponível em: $<$ http:// www.planalto.gov.br/CCIVIL_03/Leis/L9434.htm> Acesso em: 20 jun. 2018.
} 
percorreu parte do mundo, mas teve sua divulgação proibida na França por entenderem os franceses que existia uma afronta ao direito do cadáver. Ao tomar conhecimento de tal exposição a Justiça francesa determinou que as portas fossem fechadas sob pena de uma multa diária de 20 mil euros, por entender que estava se afrontando o direito ao cadáver:

O centro da questão: o uso dos corpos humanos e o direito ao cadáver. Entre nós, o estudioso Anderson Scheriber, em Direitos da personalidade, suscita a discussão a respeito de decisão dada pelo Poder Judiciário francês em 2009, a respeito da exposição À Corps Ouvert, quando a juridicização da questão ganhou ampla repercussão $0^{12}$.

A legislação brasileira tem o contorno da matéria no artigo 14 do Código Civil de 2002, sendo capaz de responder a polêmica na medida em que permite a disposição do próprio corpo, quando o ato de disposição do corpo após a morte recai sobre a manifestação de vontade de seu titular ${ }^{13}$.

A manifestação de vontade também é essencial nos casos do testamento vital permitindo a uma pessoa uma "morte digna", evitando tratamentos desnecessários para o prolongamento artificial da vida, ou que tenha benefícios ínfimos ${ }^{14}$.

Assim sendo, o cadáver somente pode ter as destinações de inumação, cremação, doação de órgãos ou doação do corpo para pesquisa ou estudo científico. Qualquer outra destinação contrária ao princípio da dignidade da pessoa humana e ao direito à integridade física deve ser combatida pela legislação e garantida pelo Judiciário, o que reforça a importância da criação de instrumentos públicos registrais na publicidade de tais temas.

\section{DO REGISTRO CIVIL E DAS PESSOAS NATURAIS FACE AO DIREITO DO CA-}

12 BITTAR, Carlos Alberto. Os direitos da Personalidade. $6^{\text {a }}$ ed. atualizada por Eduardo Carlos Bianca Bittar. Rio de Janeiro: Forense Universitária, 2003. p. 152.

${ }^{13}$ BRASIL. Lei $\mathrm{n}^{\mathrm{o}}$ 10.406, de 10 de janeiro de 2002. Institui o Código Civil. Disponível em: < http://www. planalto.gov.br/ccivil_03/leis/2002/110406.htm> Acesso em: 20 jun. 2018.

${ }^{14}$ PONA, Éverton Willian. Testamento Vital e Autonomia Privada. Fundamentos das Diretivas Antecipadas de Vontade. Curitiba: Juruá, 2015. p. 40. 


\section{DÁVER}

Ao Oficial do Registro Civil das Pessoas Naturais em conformidade com o artigo 29 da Lei 6.015/73 cabe registrar os nascimentos, os casamentos, os óbitos, a emancipação por outorga dos pais ou por sentença do juiz, a interdição por incapacidade absoluta ou relativa, a sentença declaratória de ausência ou de morte presumida, as opções de nacionalidade e as sentenças que deferirem a legitimação $\operatorname{adotiva}^{15}$.

Os registros são feitos em livros numerados sequencialmente, precedidos de uma letra de acordo com a natureza do registro ("A" para nascimento, "B" para casamento, "B-Auxiliar" para casamento religioso com efeitos civis, "C" para óbitos, "C-Auxiliar" para óbitos de natimorto, "D" Editais de Proclamas, "E" para outros registros). Feito o registro é expedida no ato uma certidão (primeira via), relatando o que consta do assento. Além da certidão expedida no ato do registro, é possível pedir certidão a qualquer tempo ( $2^{\text {as }}$ vias), e o pedido pode ser feito por qualquer pessoa, uma vez que os registros são públicos.

A Central de Informações do Registro Civil (CRC) é o portal destinado aos Cartórios de Registro Civil das Pessoas, instituída pelo Provimento $n^{\circ} 46$ do Conselho Nacional de Justiça $(\mathrm{CNJ})^{16}$, e que congrega toda a base de dados de nascimentos, casamentos, óbitos, emancipações, ausências e interdições, permitindo a localização de assentos em tempo real e a solicitação de certidões eletrônicas e digitais entre cartórios e entre cartórios e Poder Judiciário, além de uma série de outras funcionalidades.

O Assento de Óbito tem a função de atestar o falecimento de uma pessoa perante aos órgãos competentes, mediante a uma declaração de óbito (DO), sendo que o registro do óbito bem como a primeira certidão é gratuito (Lei Federal $9.534 / 1997)^{17}$. A declaração do óbito deverá ser feita no Oficial de Registro Civil da circunscrição do local do óbito, ou em conformidade com a Lei ${ }^{0}$ 13.484/2017, que

$\overline{15}$ BRASIL. Lei $\mathrm{n}^{\mathrm{0}} 6.015$, de 31 de dezembro de 1973. Dispõe sobre os registros públicos, e dá outras providências. Disponível em: < http://www.planalto.gov.br/ccivil_03/leis/L6015original.htm> Acesso em: 22 jun. 2018.

${ }^{16}$ CONSElho naCiOnal DE JUSTiÇA. Provimento $\mathbf{n}^{\mathbf{0}}$ 46, de 16 de junho de 2015. Disponível em: $<$ http://www.recivil.com.br/noticias/noticias/view/provimento-n-46-do-cnj-revoga-o-provimento-38-de-25-07-2014-e-dispoe-sobre-a-central-de-informacoes.html> Acesso em: 10 ago. 2018.

${ }^{17}$ BRASIL. Lei no 9.534, de 10 de dezembro de 1997. Dá nova redação ao art. 30 da Lei $n^{0} 6.015$, de 31 de dezembro de 1973, que dispõe sobre os registros públicos; acrescenta inciso ao art. $1^{\circ}$ da Lei ${ }^{\circ} 9.265$, de 12 de fevereiro de 1996, que trata da gratuidade dos atos necessários ao exercício da cidadania; e altera os arts. 30 e 45 da Lei $n^{\circ} 8.935$, de 18 de novembro de 1994, que dispõe sobre os serviços notariais e de registro. Disponível em: < http://www.planalto.gov.br/ccivil_03/LEIS/L9534.htm > Acesso em: 22 jun. 2018. 
altera a Lei $\mathrm{n}^{0}$ 6.015, de 31 de dezembro de 1973 (Lei de Registros Públicos), que faculta a lavratura do óbito no local da residência do falecido. A nova lei é resultado da conversão da Medida Provisória $n^{0} 776 / 2017$, com alterações posteriores inseridas na Câmara e no Senado.

O assento de óbito será lavrado pelo Oficial do Registro Civil e das Pessoas Naturais, à vista do atestado médico ou, em caso contrário, mediante declaração de duas pessoas qualificadas que tiverem presenciado ou verificado a morte. Nos locais onde houver o Serviço de Verificação de Óbitos (SVO), as declarações de óbitos serão prestadas a estes órgãos, sendo que se faz necessária a apresentação do competente atestado médico.

Neste sentido, são obrigados a fazer a declaração de óbito, o chefe de família, a respeito de sua mulher, filhos, hóspedes, agregados e fâmulos; a viúva, a respeito de seu marido, e de cada uma das pessoas indicadas no número antecedente; o filho, a respeito do pai ou da mãe; irmão, a respeito dos irmãos, e demais pessoas de casa; o parente mais próximo maior e presente; o administrador, diretor ou gerente de qualquer estabelecimento público ou particular, a respeito dos que nele faleceram, salvo se estiver presente algum parente em grau acima indicado. Na falta de pessoa competente, nos termos dos anteriores citados, a que tiver assistido aos últimos momentos do finado, o sacerdote, o médico ou vizinho que do falecimento tiver notícia; a autoridade policial, a respeito de pessoas encontradas mortas.

O declarante terá que apresentar pelo menos um dos documentos do falecido, abaixo listados: Número de registro de Carteira de Identidade e respectivo órgão emissor; Número do Cadastro de Pessoas Físicas (CPF); Número de Registro de Nascimento, com informação do livro, da folha e do termo; Número do Título de Eleitor; Número de inscrição no Instituto Nacional de Seguro Social - INSS, se contribuinte individual; Número de inscrição do PIS/PASEP; Número de benefício previdenciário-NB, se a pessoa falecida for titular de qualquer benefício pago pelo INSS; Número e série da Carteira de Trabalho.

A redação dada pela Lei 13.484/2017 à Lei nº 6.015/73 é a seguinte:

Art. 77. Nenhum sepultamento será feito sem certidão do oficial de registro do lugar do falecimento ou do lugar de residência do de cujus, quando o falecimento ocorrer em local diverso do seu domicílio, extraída após a lavratura do assento de óbito, em vista do atestado de médico, se houver no lugar, ou em caso contrário, de duas pessoas qualificadas que tiverem em presenciado ou verificado a morte (grifo nosso). 
$\S 1^{0}$ Antes de proceder ao assento de óbito de criança de menos de 1 (um) ano, o oficial verificará se houve registro de nascimento, que, em caso de falta, será previamente feito.

$\S 2^{\circ}$ A cremação de cadáver somente será feita daquele que houver manifestado a vontade de ser incinerado ou no interesse da saúde pública e se o atestado de óbito houver sido firmado por 2 (dois) médicos ou por 1 (um) médico legista e, no caso de morte violenta, depois de autorizada pela autoridade judiciária ${ }^{18}$.

Assim sendo, a Lei 13.484/2017 altera a competência para registro de óbito, podendo ser escolhido ou o Oficial do Registro Civil e das Pessoas Naturais do local do óbito ou o lugar da residência do de cujus. Neste último caso sugere-se que seja feito requerimento pelo declarante, mediante apresentação de comprovante de residência do falecido.

Também na impossibilidade de ser feito o registro dentro de 24 (vinte e quatro) horas do falecimento, pela distância, ou por qualquer outro motivo relevante, o assento será lavrado depois, com a maior urgência, sempre dentro do prazo máximo de 15 (quinze) dias, ou até dentro de 3 (três) meses para os lugares distantes mais de 30 (trinta) quilômetros da sede da Unidade de Serviço.

Existem situações em que o cadáver não é imediatamente enterrado ou cremado, mas sim destinado a uma instituição de ensino, para ser objeto de estudos e pesquisas, contribuindo consideravelmente para o ensino e formação de profissionais da área médica.

O Código Civil de 2002 ensina em seu artigo 14 que "É válida, com objetivo científico, ou altruístico, a disposição gratuita do próprio corpo, no todo ou em parte, para depois da morte. Parágrafo único. $\mathrm{O}$ ato de disposição pode ser livremente revogado a qualquer tempo"19.

Assim sendo, é perfeitamente possível que alguém disponha do próprio corpo para depois da morte e tal disposição deve observar critérios legais. Do ponto de vista da legislação positiva brasileira, o que se tem é o contorno da matéria definido pelo artigo 14 do Código Civil de 2002.

Neste diapasão Carlos Alberto Bittar ensina:

Assim, considerando não ser cabível a legislação sobre a uti-

\footnotetext{
$\overline{{ }^{18} \text { BRASIL. Lei } \mathrm{n}^{0} 13.484}$, de 26 de setembro de 2017. Altera a Lei $\mathbf{n}^{\circ}$ - 6.015, de 31 de dezembro de 1973, que dispõe sobre os registros públicos. Disponível em: < http://www.planalto.gov.br/ccivil_03/leis/L6015original.htm > Acesso em: 22 jun. 2018.

${ }_{19}$ BRASIL. Lei $\mathrm{n}^{\mathrm{o}}$ 10.406, de 10 de janeiro de 2002. Institui o Código Civil. Disponível em: <http://www. planalto.gov.br/ccivil_03/leis/2002/10406.htm> Acesso em: 20 jun. 2018.
} 
lização de cadáver não reclamado (Lei n. 8.501/1992) nem a legislação para transplante (Lei n. 9.434/1997), o dispositivo geral do Código Civil é suficiente para responder à polêmica, na inovação trazida na matéria pelo Código de 2002, na medida em que permite a disposição do próprio corpo, quando, portanto, o ato de disposição sobre o destino do corpo após a morte recai sobre a vontade de seu titular ${ }^{20}$.

Em conformidade com os artigos $1^{\circ}$ e $2^{\circ}$ da Lei 8.501/1992, os cadáveres não reclamados junto à autoridade pública no prazo de 30 (trinta) dias poderão ser destinados "às escolas de medicina, para fins de ensino e de pesquisa de caráter científico" 21 . A questão é saber como ter a certeza de se estar frente a cadáver "não reclamado" e de poder ele ser efetivamente destinado para fins de ensino e pesquisa de caráter científico?

No Estado de São Paulo o Provimento ${ }^{0} 16$ da Corregedoria Geral de Justiça das Serventias Extrajudiciais, em 23 de setembro de 1987, cuida do tema. Em nível Federal o artigo $2^{\circ}$ da Lei 8.501/1992 ensina que poderão ser destinados aos estudos de anatomia e para fins de pesquisa científica, exclusivamente, os cadáveres que preencherem, cumulativamente, aos seguintes requisitos:

I - não dispor de qualquer documentação, vale dizer, de qualquer tipo de documento que o possa identificar, seja ele emitido pelas autoridades públicas (tais como Cédula de Identidade (RG), Certificado de Reservista, Título de Eleitor - que naturalmente, estivesse em poder da pessoa que se extinguiu - ou Carteira Profissional) ou qualquer outro documento que sirva para identificar seu portador, tais como, mas não exclusivamente, Carteira ou Cédula de Identidade expedida por empresas e/ou quaisquer outros documentos que sirvam, de qualquer forma, para estabelecer sua identidade ou auxiliem a fazê-lo. II - identificado, sobre o qual inexistem informações relativas a endereços de parentes ou responsáveis legais ${ }^{22}$.

Atualmente, as Normas de Serviço da Corregedoria Geral da Justiça de São Paulo (NSCGJ/SP), na subseção II do Capítulo XVII, que trata "Do Assento de Óbito

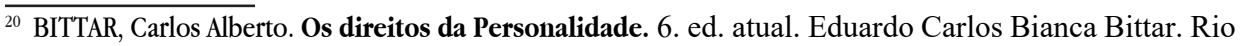
de Janeiro: Forense Universitária, 2003. p. 152.

${ }^{21}$ BRASIL. Lei $n^{\circ}$ 8.501, de 30 de novembro de 1992. Dispóe sobre a utilização de cadáver não reclamado, para fins de estudos ou pesquisas científicas e dá outras providências. Disponível em: <http://www2. camara.leg.br/legin/fed/lei/1992/lei-8501-30-novembro-1992-363726-publicacaooriginal-1-pl.html> Acesso em: 20 jun. 2018.

${ }^{22}$ Ibidem. 
de Pessoa Desconhecida e da Utilização do Cadáver para Estudos e Pesquisas", trazem no item 96:

Sendo o finado desconhecido, o assento deverá conter declaração de estatura ou medida, se for possível, cor, sinais aparentes, idade presumida, vestuário e qualquer outra indicação que possa auxiliar seu futuro reconhecimento; e no caso de ter sido encontrado morto, serão mencionados essa circunstância e o lugar em que se achava e o da necropsia, se realizada ${ }^{23}$.

O item apresentado trata do óbito de pessoa desconhecida, tanto que os elementos do assento visam auxiliar o futuro reconhecimento do falecido. Logo, esses serão os cadáveres das pessoas extintas que poderão eventualmente ser utilizados para fins de estudo de pesquisas científicas com base na Lei 8.501/1992, devendo a escola de medicina, na forma determinada pelo item 100.2 das "Normas Gerais de Serviço da Corregedoria Geral da Justiça do Estado de São Paulo":

a) requerer a lavratura do assento de óbito no Cartório de Registro Civil do local da ocorrência do falecimento, para tanto apresentando, obrigatoriamente, o atestado de óbito, o laudo da necroscopia, se for o caso e os elementos de que dispuser para demonstrar como a pessoa que se finou deu entrada nos seus Hospitais; b) para tanto, apresentará requerimento singelo, despido de maiores formalidades, salvo a expressa invocação do disposto na Lei 8.501/92 e nas "Normas Gerais de Serviço" já referidas; c) esse requerimento será autuado no Cartório de Registro Civil e lá permanecerá, devendo a escola de medicina, como determina o art.100.3 das "Normas Gerais de Serviço", promover a publicação de editais "em jornal de grande circulação", em dez dias alternados e pelo prazo de trinta dias, onde deverão constar todos os dados identificatórios disponíveis do cadáver e a possibilidade de serem dirigidas reclamações de familiares ou responsáveis legais ao oficial delegado ${ }^{24}$.

Neste caso específico o Oficial do Registro Civil e das Pessoas Naturais em conformidade com as "Normas Gerais de Serviço da Corregedoria Geral de Justiça

${ }^{23}$ CORREGEDORIA GERAL DA JUSTIÇA DE SÃO PAULO. Provimento no 41, de 18 de dezembro de 2012. Disponível em: <http://www.arpensp.org.br/?pG =X19leGlizV9ub3RpY2lhcw $==\&$ in $=$ MTczOTc $=>$ Acesso em: 20 jun. 2018.

${ }^{24}$ Ibidem. 
do Estado" é aquele do local do óbito, haja vista que não é possível aplicar as atualizações disponibilizadas pelo artigo 77 da Lei 13.484/2017, por não se saber o local da residência do falecido.

Também a Lei 9.434/1997, conhecida como Lei dos Transplantes, enfrenta questões muito delicadas nesse campo, como a "definição do momento da morte". O entendimento prevalecente é:

o de que se verifica a morte quando a alma (o espírito) se desprende do corpo (invólucro), não havendo mais possibilidade de interação entre ser e meio ambiente, ou seja, não conseguindo mais aquele responder aos estímulos externos, sendo a morte encefálica o seu mais claro e objetivo sinal de terminação da vida ${ }^{25}$.

A Lei $n^{0} 9.434 / 1997$ vai além ao estabelecer em seu artigo $3^{\circ}$ que:

A retirada post mortem de tecidos, órgãos ou partes do corpo humano, destinados a transplante ou tratamento deverá ser precedida de diagnóstico de morte encefálica, constatada e registrada por dois médicos não participantes das equipes de remoção e transplante, mediante a utilização de critérios clínicos e tecnológicos definidos por resolução do Conselho Federal de Medicina ${ }^{26}$.

A esse respeito, é colacionado abaixo, o Enunciado 277, aprovado na IV Jornada de Direito Civil:

277 - Art. 14 . O art. 14 do Código Civil, ao afirmar a validade da disposição gratuita do próprio corpo, com objetivo científico ou altruístico, para depois da morte, determinou que a manifestação expressa do doador de órgãos em vida prevalece sobre a vontade dos familiares, portanto, a aplicação do art. $4^{\circ}$ da Lei $n^{\circ}$ 9.434/1997 ficou restrita à hipótese de silêncio do potencial doador ${ }^{27}$.

Ademais, a idoneidade da instituição em que se perfaz o transplante tam-

\footnotetext{
${ }^{25}$ BITTAR, Carlos Alberto. Os direitos da Personalidade. 6. ed. atualizada por Eduardo Carlos Bianca Bittar. Rio de Janeiro: Forense Universitária, 2003. p. 151.

${ }^{26}$ BRASIL. Lei $n^{\circ} 9.434$, de 4 de fevereiro de 1997. Dispõe sobre a remoção de órgãos, tecidos e partes do corpo humano para fins de transplante e tratamento e dá outras providências. Disponível em: $<\mathrm{http} / /$ www.planalto.gov.br/CCIVIL_03/Leis/L9434.htm> Acesso em: 20 jun. 2018.

${ }^{27}$ IV JORNADA DE DIREITO CIVIL. Enunciado 277, Coordenador-Geral Ministro Ruy Rosado de Aguiar. Disponível em: < http://www.cjf.jus.br/enunciados/enunciado/227> Acesso em: 25 jul. 2018.
} 
bém deve ser observada, sem se esquecer de que a recomposição do cadáver para entrega aos parentes é uma medida que caminha retilínea com os valores do Direito da Personalidade, bem como com o Princípio da Dignidade da Pessoa Humana. Logo, quando integrada em outrem à parte destacada do cadáver, à respectiva esfera jurídica passa a pertencer para todos os efeitos naturais e jurídicos ao corpo transplantado.

\section{DA CRIAÇÃO DO LIVRO "F" - DO REGISTRO DE PARTES DO CORPO HUMA- NO NO OFICIAL DO REGISTRO CIVIL E DAS PESSOAS NATURAIS E DA “DOPC" - DECLARAÇÃO DE ÓBITO DE PARTES DO CORPO}

O membro amputado não recebe um "atestado de óbito", documento exclusivo para designar a morte de uma pessoa, que se materializa por meio da Declaração de Óbito (DO) fornecido pela Unidade de Saúde responsável pela constatação do evento morte. A orientação do Ministério da Saúde para os casos de amputação de membros é que o médico elabore um relatório, descrevendo o procedimento que foi realizado.

Neste sentido, existem dois destinos para o órgão amputado: o próprio hospital encaminha o membro para cremação, ou o paciente, desejando pode providenciar o sepultamento do membro amputado, sendo necessário um documento emitido pela unidade de saúde, geralmente um atestado.

Ademais, nos casos em que o paciente tenha dado preferência ao sepultamento do membro amputado, a família, ou o próprio paciente, deverá entrar em contato com a funerária para cuidar da retirada do membro na unidade de saúde e o encaminhar ao cemitério desejado. Trata-se de procedimento muito semelhante ao enterro de uma pessoa, sendo necessário o uso de uma "urna funerária" que normalmente é uma "infantil", haja vista que não existem urnas destinadas especialmente para os membros.

Assim sendo, o que devem ser respeitadas são as prescrições de ordem pública, em especial sanitárias, não sendo permitido ao paciente manter o membro em casa. $\mathrm{O}$ ato de resistência é punido com normas legais específicas que impedem esta prática. Configuram infrações à legislação sanitária federal o paciente insistir em 
assim agir podendo ser punido com base nas Leis $6.437 / 1977^{28}$, que estabelece as sanções respectivas e dá outras providências, bem como pela Lei $12.305 / 2010^{29}$, que institui a Política Nacional de Resíduos Sólidos.

No ano de 2013 o sítio eletrônico "Terra" forneceu informação de que no ano de 2012 o Brasil registrou cerca de 45.000 (quarenta e cinco mil) amputações (44.792) de membros inferiores e superiores feitas pelo Sistema Único de Saúde (SUS), segundo dados do Ministério da Saúde. Neste momento, diante da perda física de membros e do emocional totalmente abalado o paciente ainda se depara com a questão legal: qual o destino que deve ser dado à parte do corpo retirada? O sepultamento de seres humanos após a morte é bem regulamentado, porém, o que fazer com o braço, perna ou qualquer outra parte amputada? Os membros, assim como os mortos, também devem possuir declaração de óbito para serem enterrados? ${ }^{30}$

Neste diapasão, o que se observa é a necessidade urgente de regulamentação deste tema. A ligação do Direito da Personalidade e o cuidado pelo Princípio da Dignidade da Pessoa Humana demonstram quão importante é a necessidade de regulamentação. A falta de legislação determinando o destino de "partes do corpo amputado" demonstra um abandono legislativo do tema que influencia diretamente no direito da personalidade.

Os registros no "Livro F" - de partes do corpo humano amputado - feitos pelo Oficial do Registro Civil e das Pessoas Naturais é o meio garantidor deste direito, haja vista que os "Novos Assentos" garantirão a publicidade, destino, respeito e perpetuidade das informações registrais. $\mathrm{O}$ destino que deve ser dado à parte do corpo retirada está intimamente ligado à Teoria do Prolongamento do Direito ao Corpo Vivo, tornando por isso concreto este caractere de perpetuidade de certos direitos da personalidade.

Nesse sentido, goza esse direito das prerrogativas comuns aos direitos da personalidade, sendo o sepultamento de seres humanos após a morte regulamen-

$\overline{{ }^{28} \text { BRASIL. Lei } \mathrm{n}^{\circ} 6.437}$, de 20 de agosto de 1977 . Configura infrações à legislação sanitária federal, estabelece as sanções respectivas, e dá outras providências. Disponível em: < http://www.camara.gov.br/sileg/ integras/455672.pdf > Acesso em: 20 jun. 2018.

${ }^{29}$ BRASIL. Lei $\mathrm{n}^{\mathrm{O}} 12.305$, de 2 de agosto de 2010. Institui a Política Nacional de Resíduos Sólidos; altera a Lei no 9.605, de 12 de fevereiro de 1998; e dá outras providências. Disponível em: < http://www.planalto.gov. br/ccivil_03/_Ato2007-2010/2010/Lei/L12305.htm> Acesso em: 20 jun. 2018.

${ }^{30} \mathrm{O}$ que fazer com um membro amputado? Posso levar para casa? No Brasil, não é permitido ao paciente manter o membro em casa, e tal ato pode ser punido com normas legais específicas que impedem a prática, Terra, 02 nov. 2013. Disponível em: < https://www.terra.com.br/noticias/educacao/voce-sabia/o-que-fazer-com-um-membro-amputado-posso-levar-para-casa,c137e2a2c7a02410VgnVCM10000098cceb0aRCRD.html.> Acesso em: 17 jul. 2018. 
tada, porém o que fazer com o braço, perna ou qualquer outra parte amputada é o "X" da questão.

Os sepultamentos de partes do corpo humano devem passar pelas mesmas formalidades legais que passam o sepultamento de seres humanos, devendo os Assentos lavrados no "Livro F" dos Oficiais do Registro Civil e das Pessoas Naturais serem formalizados como meio garantidor do direito da personalidade, principalmente por tal tema ser tão relevante na proteção de outros direitos decorrentes deste primeiro, tais como direitos trabalhistas, previdenciários e até mesmo legislações especiais como o Estatuto da Pessoa com Deficiência.

Neste sentido, os membros, assim como os mortos, também devem possuir declaração de óbito para serem enterrados. A Declaração de Óbito (DO) como documento-base do Sistema de Informações sobre Mortalidade do Ministério da Saúde (SIM/MS) é composta de três vias autocopiativas, prenumeradas sequencialmente, fornecidas pelo Ministério da Saúde e distribuídas pelas Secretarias Estaduais e Municipais de Saúde conforme fluxo padronizado para todo o Brasil.

Os dados de óbitos são utilizados para conhecer a situação de saúde da população e gerar ações visando a sua melhoria. Para tanto, devem ser fidedignos e refletir a realidade. As estatísticas de mortalidade são produzidas com base na DO emitida pelo médico. Logo, a criação da DOPC (Declaração de Óbito de Parte do Corpo) estará proporcionando um conhecimento maior da saúde desta população que passa pela infelicidade de amputação de membros.

Atualmente existem duas situações em que não é necessário emitir a DO (Declaração de Óbito). No caso de óbito fetal, com gestação de menos de 20 semanas, ou feto com peso menor que 500 gramas, ou estatura menor que 25 centímetros, a legislação atual permite que, na prática, a emissão da DO seja facultativa para os casos em que a família queira realizar o sepultamento do produto de concepção.

Também, para peças anatômicas retiradas por ato cirúrgico ou de membros amputados, o médico elaborará um relatório em papel timbrado do hospital descrevendo o procedimento realizado. Esse documento será levado ao cemitério, caso o destino da peça venha a ser o sepultamento. O que se observa é que, tanto o primeiro caso (gestação de menos de 20 semanas) salvo a facultatividade, como também no segundo (amputação de membros) não será emitido a Declaração de Óbito por falta de legislação que garanta estes direitos da personalidade.

No entanto, no caso de óbito fetal, se a gestação teve duração igual ou su- 
perior a 20 semanas, ou o feto com peso igual ou superior a 500 gramas, ou estatura igual ou superior a 25 centímetros, será emitido Assento de Óbito de Natimorto, o qual será lavrado no "Livro C Auxiliar" do Oficial do Registro Civil e das Pessoas Naturais.

As criações do "Livro F" - registros de partes do corpo e da DOPC - (Declaração de Óbito de Parte do Corpo) estarão consolidando estes direitos enraizados na teoria do prolongamento do direito ao corpo vivo, tornando por isso concreto este caractere de perpetuidade de certos direitos da personalidade.

Quando negado o registro de partes do corpo humano no Oficial do Registro Civil e das Pessoas Naturais às pessoas desprotegidas pela falta de legislação que determine a lavratura de Assento de Óbito de Parte do Corpo Humano, elas se deparam com a lacuna legislativa estabelecida por omissão do próprio Estado Legislador na criação de mecanismo hábil da proteção deste direito da personalidade.

Aos médicos é proibido emitir DO (Declaração de Óbito) para o caso de amputação, estando a legislação vigente violando o Princípio de Dignidade da Pessoa Humana, pois no Oficial do Registro Civil e das Pessoas Naturais não é possível qualquer tipo de publicidade e registro e no plano sanitário existe a necessidade de conferir-lhe com a máxima brevidade o destino de partes do corpo humano ante o processo natural de decomposição.

\section{DA TUTELA PENAL E CIVIL DO CADÁVER}

De Cupis ${ }^{31}$ advoga que o corpo humano após a morte torna-se coisa, classificando-se entre as coisas extra-commercium. O uso de cadáver exige prova inconteste da morte, autorização expressa do disponente ou dos parentes indicados na lei, gratuidade da licença, devendo a operação efetivar-se por médico habilitado e identificado, sendo para fins terapêuticos ou científicos.

Aconselha-se que a operação seja concretizada por médico distinto daquele que atestou a morte. A retirada de um órgão ou parte deste como tolhos, coração e rinsł deve respeitar a integridade do cadáver, devendo evitar mutilações desnecessárias que atentem o respeito devido aos mortos, ocorrendo o transplante de partes essenciais para o uso futuro.

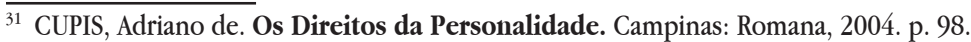


O Código Penal brasileiro visando à proteção do direito ao cadáver estabelece algumas figuras tuteladas pelo direito penal, tais como impedimentos ou perturbação de cerimônia funerária e enterro (artigo 209); violação de sepultura (artigo 210); destruição, subtração ou ocultação de cadáver (artigo 211); vilipêndio a cadáver e suas cinzas (artigo 212) ) $^{32}$.

O Capítulo II - DOS CRIMES CONTRA O RESPEITO AOS MORTOS, no Código Penal brasileiro, estabelece:

Art. 209 - Impedir ou perturbar enterro ou cerimônia funerária: Pena - detenção, de um mês a um ano, ou multa. Parágrafo único - Se há emprego de violência, a pena é aumentada de um terço, sem prejuízo da correspondente à violência.

Art. 210 - Violar ou profanar sepultura ou urna funerária: Pena - reclusão, de um a três anos, e multa.

Art. 211 - Destruir, subtrair ou ocultar cadáver ou parte dele: Pena - reclusão, de um a três anos, e multa.

Art. 212 - Vilipendiar cadáver ou suas cinzas: Pena - detenção, de um a três anos, e multa ${ }^{33}$.

O ordenamento jurídico brasileiro visando à proteção dos direitos inerentes às pessoas e buscando a pacificação social determina regras de comportamentos que devem ser seguidas. Dentre essas normas há uma proteção especial em relação ao cadáver, que, através da interpretação do artigo 12 do Código Civil Brasileiro, chega-se à conclusão de que os direitos da personalidade se estendem ao falecido:

Artigo 12. Pode-se exigir que cesse a ameaça, ou a lesão, a direito da personalidade, e reclamar perdas e danos, sem prejuízo de outras sanções previstas em lei. Parágrafo único. Em se tratando de morto, terá legitimação para requerer a medida prevista neste artigo o cônjuge sobrevivente, ou qualquer parente em linha reta, ou colateral até o quarto grau ${ }^{34}$.

Além do mais, a extensão dos direitos da personalidade ao cadáver após a morte com base na "Teoria do Prolongamento do Direito ao Corpo Vivo", confirma que os direitos remanescem com a morte. Existe também a possibilidade de o

\footnotetext{
32 BRASIL. Decreto-Lei n ${ }^{\circ} 2.848$, de 7 de dezembro de 1940. Código Penal. Disponível em: <http://www.planalto.gov.br/ccivil_03/decreto-lei/Del2848compilado.htm> Acesso em: 20 jun. 2018.

33 Ibidem.

${ }^{34}$ BRASIL. Lei $\mathrm{n}^{\mathrm{o}}$ 10.406, de 10 de janeiro de 2002. Institui o Código Civil. Disponível em: <http://www. planalto.gov.br/ccivil_03/leis/2002/10406.htm> Acesso em: 20 jun. 2018.
} 
falecido deixar determinada qual a sua vontade para após a morte, devendo toda destinação digna de vontade prevalecer.

Não existindo nada que disponha sobre sua destinação, aos familiares competirá determinar o destino dado ao cadáver com base nas limitações legais, haja vista que o fim da vida não configura o fim dos direitos do cadáver.

O cadáver possui proteção jurídica, o que é observado pelas leis existentes, ou seja, Lei $n^{0} 8.501 / 92$, que dispõe sobre a destinação de cadáveres não reclamados junto às autoridades públicas, Lei ${ }^{0} 9.434 / 1997$, que dispõe sobre a remoção de Órgãos, Tecidos e Partes do Corpo Humano para fins de transplante e tratamento e dá outras providências, bem como artigo 12 do Código Civil Brasileiro, artigos 209, 210, 211 e 212 do Código Penal Brasileiro e o próprio artigo $1^{\circ}$, inciso III da Constituição Federal do Brasil de 1988.

A morte não retira a dignidade da pessoa falecida e o Estado tem o dever de proteger todos os direitos. O cadáver pode ser vítima de alguma ofensa à sua memória, ou até mesmo ter uma destinação diversa do que estabelece a lei ou o ato de disposição de última vontade. O direito ao cadáver está diretamente relacionado ao direito à integridade física, pois os primeiros estudos jurídicos acerca do assunto se iniciaram com a possibilidade de retirada das partes do corpo enquanto vivo.

O direito português desde o passado consegue visualizar o cadáver como "Coisa". Para Szaniawski ${ }^{35}$, a natureza jurídica estabelecida para o cadáver é de direito de propriedade. Já De Cupis é divergente no sentido de que a morte não coloca um fim nos direitos da personalidade e quanto à natureza jurídica do cadáver, sendo que "o corpo humano, depois da morte, torna-se uma coisa submetida à disciplina jurídica, coisa, no entanto, que não podendo ser objeto de direitos privados patrimoniais, deve classificar-se entre as coisas extra commercium"36.

A pessoa, enquanto viva, não pode ser objeto de comércio, ou seja, objeto de direitos patrimoniais, conforme o espírito legislativo do artigo 14 do Código Civil de 2002. Logo não pode ser o cadáver que conserva o resíduo de pessoa viva, em conformidade com a Teoria do Prolongamento do Corpo Vivo. Já De Cupis assevera que o corpo do morto deve ser tratado como uma coisa, mas uma coisa fora do comércio $^{37}$.

\footnotetext{
35 SZANIAWSKI, Elimar. Direitos de Personalidade e sua Tutela. São Paulo: Revista dos Tribunais, 1993. p. 304.

${ }^{36}$ CUPIS, Adriano de. Os Direitos da Personalidade. Campinas: Romana, 2004. p. 98.

${ }^{37}$ Ibidem.
} 
A posição que prevalece nos dias atuais é a que determina que a natureza jurídica do cadáver seja um direito pessoal, ou seja, o cadáver não pode ser considerado coisa, não existindo direitos patrimoniais, mas sim um direito pessoal transmitido aos herdeiros e caso não haja disposição de última vontade (manifestação de vontade) o destino deve ser em conformidade com o Princípio da Dignidade da Pessoa Humana e as disposições legais.

Neste sentido, uma sentença portuguesa de 31 de agosto de 1847 discutiu a propriedade do cadáver da mulher de "Vieira de Castro" considerando que: "Eis a Ementa: o cadáver da mulher assassinada pelo marido pertence aos parentes dela e não ao marido ou parentes dele"38.

O direito da personalidade do cadáver e de partes do corpo humano é um bem jurídico essencial sobre o qual reconhece a ordem legal um direito subjetivo, pessoal, inconfundível com os direitos subjetivos de expressão patrimonial, não podendo existir "circulabilidade negocial" como ocorre com os bens imóveis, podendo existir apenas disposição gratuita do corpo vivo ou morto ${ }^{39}$.

A proteção post-mortem de alguns direitos da personalidade previstos no ordenamento jurídico pátrio está muito além do corpo físico vivo, superando a materialidade concreta e se inspirando nos sentimentos humanos mais puros como o amor e a saudade. O respeito pelo próximo e a existência de legislação registral compatível com os anseios sociais são fundamentais, principalmente quando se visualiza a criação do Livro "F" - registro de partes do corpo humano, na defesa dos direitos da personalidade por todos que passarão pelo "evento morte".

\section{IDEOLOGIA DE PROJETO DE LEI FEDERAL (CRIAÇÃO DO LIVRO "F" e CRIA- ÇÃO DA “DOPC”) ALTERANDO A LEI 6.015/1973}

Com o objetivo de participar do crescimento do Ordenamento Jurídico brasileiro e o respeito pelo direito da personalidade e o Princípio da Dignidade da Pessoa Humana foi idealizado o presente PROJETO DE LEI com o objetivo de suprir os direitos da personalidade daqueles que passam pela dolorosa provação de terem

\footnotetext{
${ }^{38}$ MARTINS, Antônio Carvalho. A colheita de órgãos e tecidos nós cadáveres. Coimbra: Coimbra, 1986. p. 34-35.

39 BARRETO, Wanderlei de Paula. In: ALVIN, Arruda; ALVIN, Thereza (Coord.). Comentário ao Código Civil Brasileiro. v. 1. Rio de Janeiro: Forense, 2005. p. 134.
} 
partes do corpo humano "amputado" e da necessidade cotidiana dos Oficiais do Registro Civil e das Pessoas Naturais da República Federativa do Brasil em darem segurança e publicidade das informações àqueles que dela necessitam:

\section{IDEOLOGIA DO PROJETO DE LEI}

Altera a Lei $\mathrm{n}^{0}$ 6.015, de 31 de Dezembro de 1973, que dispõe dos registros públicos, e dá outras providências.

O CONGRESSO NACIONAL decreta:

Art. $1^{\circ}$ A Lei ${ }^{0} 6.015$, de 31 de Dezembro de 1973, passa a vigorar com as seguintes alterações:

Art. 29 Serão registrados no registro civil de pessoas naturais:

IX - os membros partes do corpo humano. (NR)

Art. 33 Haverá, em cada cartório, os seguintes livros, todos com 300 (trezentas) folhas cada um:

VII - "E" - emancipações; (NR)

VIII - "F" - os membros partes do corpo humano. (NR)

Art. 79 A. São obrigados a fazer declaração de óbitos de membros parte do corpo humano.

I - aquele que sofreu a amputação;

II - pai, mãe, avô, avó, marido, esposa, companheiro, companheira, netos e colaterais até o terceiro grau;

III - o filho, a respeito do pai ou da mãe; o irmão, a respeito dos irmãos e demais pessoas de casa, indicadas no inciso II; o parente mais próximo maior e presente;

IV - o administrador, diretor, ou gerente de qualquer estabelecimento público ou particular, a respeito dos que nele tiverem membros amputados, salvo se estiver presente algum parente em grau acima indicado;

$\mathrm{V}$ - o médico na falta de pessoa competente, nos termos dos números anteriores;

VI - a autoridade policial, os militares e os oficiais do registro civil e das 
pessoas naturais.

Parágrafo único. A declaração de óbito de parte do corpo humano poderá ser feita por meio de preposto, autorizando-o o declarante em escrito, de que constem os elementos necessários ao assento de óbito de partes do corpo humano.

Art. 80 A. O assento de óbito de parte do corpo humano deverá conter:

I - a hora, se possível, dia, mês e ano da amputação;

II - o lugar da amputação, com indicação precisa;

III - o prenome, nome, sexo, idade, cor, estado civil, profissão, naturalidade, domicílio e residência da pessoa que teve seu membro amputado;

IV - o cartório do nascimento;

$\mathrm{V}$ - os nomes, prenomes, profissão, naturalidade e residência dos pais;

VI - lugar do sepultamento;

VII - pelo menos uma das informações a seguir arroladas: número de inscrição do PIS/PASEP; número de inscrição no Instituto Nacional do Seguro Social - INSS, se contribuinte individual; número de benefício previdenciário - NB; número do CPF; número de registro da Carteira de Identidade e respectivo órgão emissor; número do título de eleitor; número do registro de nascimento, com informação do livro, da folha e do termo; número e série da Carteira de Trabalho.

CAPÍTULO X Da Emancipação, Partes do Corpo Humano, Interdição e Ausência

Art. 89. Nos Oficiais do Registro Civil e das Pessoas Naturais de cada Município serão registrados no Livro "E" as sentenças de emancipação, bem como os atos dos pais que a concederem, em relação aos filhos relativamente incapazes. (NR)

Art. 89 A. Nos Oficiais do Registro Civil e das Pessoas Naturais de cada Município serão registrados no Livro "F" os membros de partes do corpo humano acompanhados da necessária DOPC (Declaração de Óbito de Partes do Corpo) fornecidas pelo Ministério da Saúde.

Art. 107 A. O óbito de parte do corpo humano deverá ser anotado, com as remissões recíprocas, nos assentos de casamento e nascimento.

Brasília, ... 
O atestado de amputação se mostra o único instrumento, na atualidade, capaz de gerar um pouco de dignidade para aqueles que passam pela dolorosa condição de ter um membro do corpo humano amputado. O parecer CREMEC no 09/2012 de 20/04/2012 Processo - Consulta Protocolo CREMEC 3072/2012, a interessada é a Dra. Wanda Santos Andrade. ASSUNTO: DECLARAÇÃO DE ÓBITO PARA MEMBROS AMPUTADOS. RELATOR: DR. JOSÉ MÁLBIO OLIVEIRA ROLIM. EMENTA: Não é cabível a Declaração de Óbito em casos de peças anatômicas amputadas, tendo em vista que não se teve um óbito. Deverá ser elaborado relatório cirúrgico, assinado pelo médico responsável pela amputação do membro, para fins de sepultamento ${ }^{40}$.

Neste sentido, uma garantia do médico que realiza a amputação do membro é exigir do paciente ou responsável autorização escrita, concordando com a amputação do membro, detalhando a situação e explicando a necessidade técnico-médica-terapêutica daquela atitude. $\mathrm{O}$ médico que não tomar este cuidado poderá responder por crime de lesão corporal grave, conforme previsto no artigo $129, \S 1^{\circ}$, inciso III, do Código Penal ${ }^{41}$.

Por fim, lembramos que membro amputado atualmente não requer Declaração de Óbito, justamente porque não existe previsão legal. A criação de Declaração de Óbito de Parte do Corpo Humano (DOPC) é o meio hábil capaz de gerar o exercício da dignidade humana, principalmente a criação do Livro " $F$ " nos Oficiais do Registro Civil e das Pessoas Naturais dos Municípios brasileiros, que será o responsável pelo registro do membro amputado.

\section{CONSIDERAÇÕES FINAIS}

No âmbito dos direitos da personalidade, advindos da dignidade humana, inclui-se o direito ao corpo, destinado a proteger a vida e a integridade física, a possibilitar ao seu sujeito diferentes formas de agir, revelando a autodeterminação do titular com a possibilidade de disposição limitada do corpo, atendendo às peculiaridades do caso.

Os direitos da personalidade estão diretamente relacionados aos atributos

\footnotetext{
${ }^{40}$ CONSELHO REGIONAL DE MEDICINA DO ESTADO DO CEARÁ. Parecer CREMEC n⿳0 09/2012, de 20 de abril de 2012. Disponível em: < http://www.cremec.com.br/pareceres/2012/par0912.pdf> Acesso em: 25 jul. 2018.

${ }^{41}$ BRASIL. Decreto-Lei $\mathrm{n}^{\circ} 2.848$, de 7 de dezembro de 1940. Código Penal. Disponível em: <http://www.planalto.gov.br/ccivil_03/decreto-lei/Del2848compilado.htm> Acesso em: 20 jun. 2018.
} 
da pessoa humana. O princípio da dignidade da pessoa humana estabelece uma garantia dos direitos daqueles que passam pela dolorosa experiência de terem um membro amputado e buscam no Oficial do Registro Civil e das Pessoas Naturais o registro e publicidade de tal acontecimento.

As partes do corpo humano, ou o próprio cadáver não pode ser considerado "coisa" conforme a visão do Livro do Direito das Coisas, haja vista que o próprio artigo 14 do Código Civil brasileiro veda a comercialidade do corpo humano, o qual deve ser usado com objetivo científico ou altruístico, respeitando a manifestação de vontade e o entendimento do que venha a ser autonomia privada.

A problemática se depara no fato de não existir previsão legal de registro de partes do corpo humano, o que ocasiona na ausência legislativa em buscar garantir estes direitos. A criação do Livro "F" no Oficial do Registro Civil e das Pessoas Naturais, o qual será responsável pelo Assento de Registro de Partes do Corpo Humano é o meio hábil capaz de proteção deste direito da personalidade.

A "Teoria do Prolongamento do Corpo Humano Vivo" é fruto do entendimento que o corpo vivo transfere ao corpo morto ou aos membros amputados direitos da personalidade decorrentes de sua anterior condição, ou seja, partes do corpo humano ou o próprio cadáver possuem direitos personalíssimos que transcendem ao corpo vivo.

Essa extensão dos direitos da personalidade ao cadáver está diretamente relacionada ao princípio da dignidade da pessoa humana e ao direito à integridade física, pois não se pode conceber afronta à honra, à imagem, ao corpo do falecido, simplesmente porque o mesmo morreu. A criação pelo Ministério da Saúde da Declaração de Óbito de Partes do Corpo (DOPC) é uma contribuição ao tema, principalmente por gerar mecanismo necessário na Lavratura de Assento de Partes do Corpo Humano no Oficial do Registro Civil e das Pessoas Naturais dos Municípios brasileiros.

\section{REFERÊNCIAS}

BARRETO, Wanderlei de Paula. In: ALVIN, Arruda; ALVIN, Thereza (Coord). Comentário ao Código Civil Brasileiro. v. 1. Rio de Janeiro: Forense, 2005.

BRASIL. Constituição da República Federativa do Brasil. Brasília: Senado Fede- 
ral, 1988. Disponível em: < http://www.planalto.gov.br/ccivil_03/constituicao/Constituicao.htm > Acesso em: 20 ago. 2016.

BRASIL. Decreto-Lei n ${ }^{\circ} 2.848$, de 7 de dezembro de 1940. Código Penal. Disponível em: <http://www.planalto.gov.br/ccivil_03/decreto-lei/Del2848compilado.htm> Acesso em: 20 jun. 2018.

BRASIL. Lei $\mathrm{n}^{\mathrm{o}} 10.406$, de 10 de janeiro de 2002. Institui o Código Civil. Disponível em: < http://www.planalto.gov.br/ccivil_03/leis/2002/10406.htm> Acesso em: 20 jun. 2018.

BRASIL. Lei no 6.015, de 31 de dezembro de 1973. Dispõe sobre os registros públicos, e dá outras providências. Disponível em: <http://www.planalto.gov.br/ ccivil_03/leis/L6015original.htm > Acesso em: 22 jun. 2018.

BRASIL. Lei $\mathrm{n}^{\mathrm{o}}$ 6.437, de 20 de agosto de 1977 Configura infrações à legislação sanitária federal, estabelece as sanções respectivas, e dá outras providências. Disponível em: < http://www.camara.gov.br/ sileg/integras/455672.pdf > Acesso em: 20 jun. 2018.

BRASIL. Lei $\mathrm{n}^{\circ}$ 8.501, de 30 de novembro de 1992. Dispóe sobre a utilização de cadáver não reclamado, para fins de estudos ou pesquisas científicas e dá outras providências. Disponível em: < http://www2.camara.leg.br/legin/fed/lei/1992/ lei-8501-30-novembro-1992-363726-publicacaooriginal-1-pl.html> Acesso em: 20 jun. 2018.

BRASIL. Lei n ${ }^{\circ} 9.434$, de 4 de fevereiro de 1997. Dispõe sobre a remoção de órgãos, tecidos e partes do corpo humano para fins de transplante e tratamento e dá outras providências. Disponível em: < http://www.planalto.gov.br/CCIVIL_03/ Leis/L9434.htm> Acesso em: 20 jun. 2018.

BRASIL. Lei $n^{0} 9.534$, de 10 de dezembro de 1997. Dá nova redação ao art. 30 da Lei $n^{0}$ 6.015, de 31 de dezembro de 1973, que dispõe sobre os registros públicos; acrescenta inciso ao art. $1^{\circ}$ da Lei $\mathbf{n}^{0} 9.265$, de 12 de fevereiro de 1996, que trata da gratuidade dos atos necessários ao exercício da cidadania; e altera os arts. 30 e 45 da Lei no 8.935, de 18 de novembro de 1994, que dispóe sobre os serviços notariais e de registro. Disponível em: < http://www.planalto. gov.br/ccivil_03/LEIS/L9534.htm> Acesso em: 22 jun. 2018. 
BRASIL. Lei $\mathrm{n}^{\mathrm{o}} 12.305$, de 2 de agosto de 2010. Institui a Política Nacional de Resíduos Sólidos; altera a Lei no 9.605, de 12 de fevereiro de 1998; e dá outras providências. Disponível em: <http://www. planalto.gov.br/ccivil_03/_Ato2007-2010/2010/Lei/L12305.htm> Acesso em: 20 jun. 2018.

BRASIL. Lei $\mathrm{n}^{\mathrm{o}} 13.484$, de 26 de setembro de 2017. Altera a Lei $\mathbf{n}^{\circ} \mathbf{6 . 0 1 5}$, de 31 de dezembro de 1973, que dispóe sobre os registros públicos. Disponível em: $<$ http://www.planalto.gov.br/ccivil_03/leis/L6015original.htm> Acesso em: 22 jun. 2018.

BITTAR, Carlos Alberto. Os direitos da Personalidade. $6^{\text {a }}$ ed. atualizada por Eduardo Carlos Bianca Bittar. Rio de Janeiro: Forense Universitária, 2003.

CONSELHO NACIONAL DE JUSTIÇA. Provimento $\mathbf{n}^{\mathbf{0}}$ 46, de 16 de junho de 2015. Disponível em: <http://www.recivil.com.br/noticias/noticias/view/provimento-n-46-do-cnj-revoga-o-provimento-38-de-25-07-2014-e-dispoe-sobre-a-central-de-informacoes.html> Acesso em: 10 ago. 2018.

CONSELHO REGIONAL DE MEDICINA DO ESTADO DO CEARÁ. Parecer CREMEC no 09/2012, de 20 de abril de 2012. Disponível em: < http://www.cremec.com.br/ pareceres/2012/par0912.pdf> Acesso em: 25 jul. 2018.

CORREGEDORIA GERAL DA JUSTIÇA DE SÃO PAULO. Provimento $\mathbf{n}^{\mathbf{0}} \mathbf{4 1}$, de 18 de dezembro de 2012. Disponível em: < http://www.arpensp.org.br/?pG=X19leGlizV9ub3RpY2lhcw $==\&$ in $=$ MTczOTc $=>$ Acesso em: 20 jun. 2018.

CUPIS, Adriano de. Os Direitos da Personalidade. Campinas: Romana, 2004.

IV JORNADA DE DIREITO CIVIL. Enunciado 277, Coordenador-Geral Ministro Ruy Rosado de Aguiar. Disponível em: < http://www.cjf.jus.br/enunciados/enunciado/227> Acesso em: 25 jul. 2018.

MARTINS, Antônio Carvalho. A colheita de órgãos e tecidos nos cadáveres. Coimbra: Coimbra, 1986.

O que fazer com um membro amputado? Posso levar para casa? No Brasil, não é permitido ao paciente manter o membro em casa, e tal ato pode ser punido com normas legais específicas que impedem a prática, Terra, 02 nov. 2013. Disponível 
em: <https://www.terra.com.br/noticias/educacao/voce-sabia/o-que-fazer-com-um-membro-amputado-posso-levar-para-casa,c137e2a2c7a02410VgnVCM10000098cceb0aRCRD.html. > Acesso em: 17 jul. 2018.

PONA, Éverton Willian. Testamento Vital e Autonomia Privada. Fundamentos das Diretivas Antecipadas de Vontade. Curitiba: Juruá, 2015.

SILVA, Justino Adriano Farias da. Tratado do direito funerário. São Paulo: Método, 2000 .

SZANIAWSKI, Elimar. Direitos de Personalidade e sua Tutela. São Paulo: Revista dos Tribunais, 1993.

Recebido em: 19/06/2018

Aceito em: 28/09/2018 